\title{
Production of Pigments on the Basis of Titanium Tetrachloride
}

\author{
Alexander Vyboishchik ${ }^{1, *}$, and Mikhail Popov ${ }^{1}$ \\ ${ }^{1}$ South Urals State University, Russia, 454080, Chelyabinsk, Lenin Ave. 76
}

\begin{abstract}
The article describes the manufacture of titanium dioxide, or titania, on the basis of titanium tetrachloride. The main technological requirements for the production of titania are listed, the most prospective raw materials for the chlorination method are given, the description of the technological process for the yield of titania is described.
\end{abstract}

\section{Introduction}

Titania, or titanium dioxide $[1,2,3,4,5]$, is a polymorphous pigment found naturally in several crystal modifications. Titania forms solid solutions with transition metal oxides hereby distorting its crystal lattice and acquiring a coloured tinge. The phenomena of phototropy and photochemical activity are also inherent in titania.

As is known [5,6,7], titania has found wide application in various industries, viz. chemical $[8,9,10,11,12,13,14]$, metallurgical [15], biochemical [16], medical $[17,18,19]$, environmental [20], recycling [21]. The production of titania is a promising direction of the current chemical branch of industry.

Ttania is manufactured from titanium tetrachloride by various methods, including chlorination $[22,23]$.

\section{Requirements for the yield of titania}

To produce any kind of pigment, including titania [22,23], the following requirements must be fulfilled:

1. The sufficient amount of direct and auxiliary materials of the specified quality.

2. The main and auxiliary equipment of the specified capacity.

3. The power (viz. electric energy, technical and fresh water, steam, etc.) and human resources of the specified amount.

4. The economically achievable technology for the production of the specified high quality product.

\footnotetext{
${ }^{*}$ Corresponding author: alex_vyb@list.ru
} 


\section{Preparation of titanium raw materials for the yield of titania from titanium tetrachloride}

The technology of titanium slag chlorination has been developed and applied at titaniummagnesium plants in order to yield titania, by means of the chlorination method. Machinebuilding enterprises produce special equipment both for slag chlorination, and for titanium tetrachloride purification. An example of such equipment is an oxidation unit for titanium tetrachloride, which is supplied with an arc plasmatron having annual yield capacity equal to 3000 tons of titania. The quality of titania yielded in this unit is on a level with the quality of titania yielded by the sulphatation method.

The most promising raw material for the yield of titania by the chlorination method is a titanium-quartz ore deposit, with the ore purification technology developed at a specially built ore processing plant. The plant has a yield capacity equal to 240 thousand tons of titanium concentrate containing $50 \ldots 52 \%$ of titania; $41 \ldots 45 \%$ of silica; $2 \ldots 3.5 \%$ of ferric oxide; $2 \ldots 3 \%$ of alumina; $0.5 \ldots 1.0 \%$ of sodium oxide; $0.06 \%$ of sulphur and $0.18 \%$ of phosphorus pentoxide.

The technology of silica pressure leaching with sodium hydroxide applied for initial concentration of ilmenite has been developed and tested in order to yield titanium-silicon of a higher concentration value than has been applied by far. When processing by pressure leaching, two chemical products are obtained: titanium-processed concentrate containing 88 ... $90 \%$ of titania and alkaline-siliceous solutions subsequently subject to filtration, crystallization and centrifugation, and finally converted into sodium metasilicate [24].

It has been stated that the supply of rutile concentrate containing $94 \ldots 95 \%$ of titania from ore processing factories provides the most economically reasonable yield of titania further on.

\section{Development of the technology for the yield of titania from titanium tetrachloride}

As it was stated above, various technologies for titanium slag chlorination, also of titanium tetrachloride purification, and titanium tetrachloride oxidation with oxygen and preliminary heating of reagents have been developed at a titanium-magnesium plant with annual yield capacity equal to 3000 tons. The technology of titanium concentrate chlorination, and titanium tetrachloride oxidation with oxygen using arc plasmatron heating has been developed at a pilot plant with annual yield capacity equal to 200 tons of titania. The quality of titania produced in this unit is on a level with the best foreign samples.

The pilot plant affords full facilities not only for testing the obtaining technology of high quality anatase-phase and rutile-phase titania, but also for titania modification with the obtaining of different-purpose pigment grades.

The research of the surface condition of titania samples obtained by the chlorination method has stated that the electric double layer of titania samples consists mainly of components of acid-base dissociation of alumina, which has a significant effect on the properties of the electric double layer and the $\mathrm{pH}$ value of the isotopes. The $\mathrm{pH}$ value of the isoelectric point and the isoelectric adsorption point of $\mathrm{H}+$ and $\mathrm{OH}$ - ions are close to each other and both equal to $6.5 \ldots 8.0$ [25].

Based on the research given, there has been developed a technological process for tiitania modification. The process flow diagram is shown in Fig. 1. 


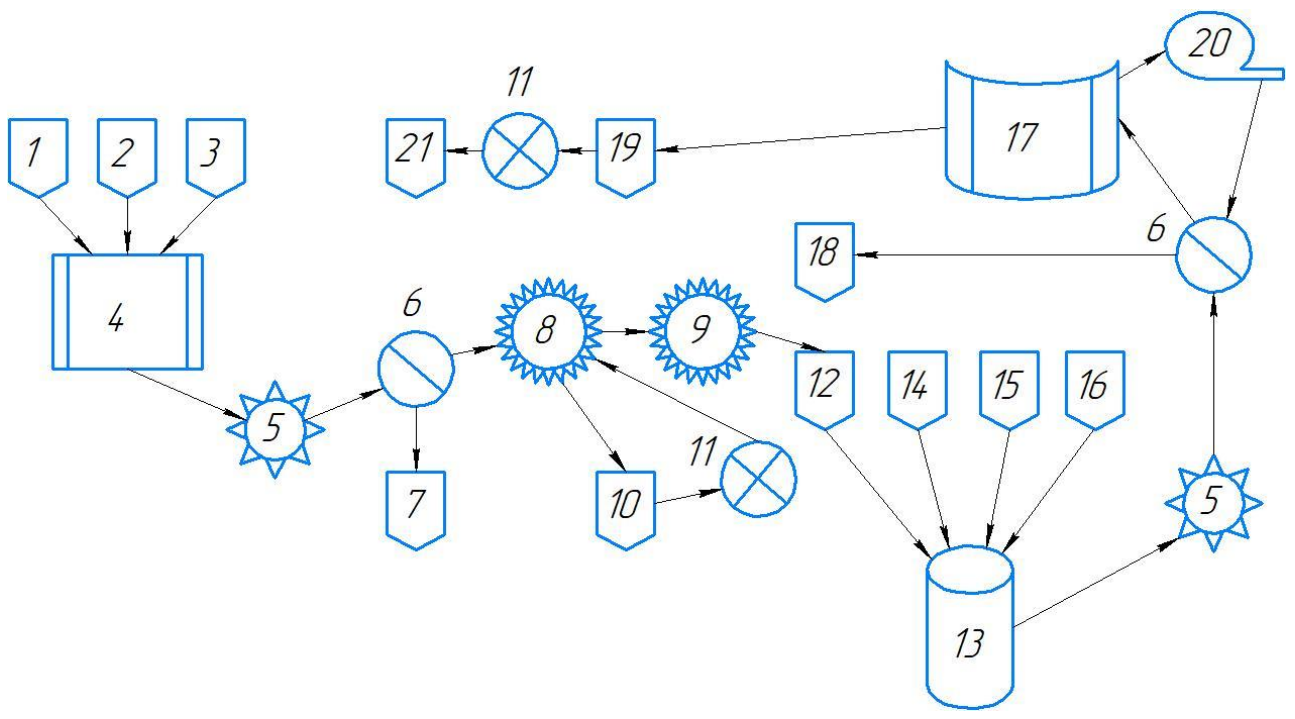

Fig. 1. Technological process of titania modification: 1 - untreated titania hopper, 2 - caustic magnesite hopper, 3 - tank for purified water or condensate, 4 - bead mill, 5 - slurry transferring pump, 6 - filter press, 7 - filtrate receiver, 8 - centrifuge, 9 - hydroseparator, 10 - coarse fraction receiver, 11 - steam-jet mill, 12 - fine fraction receiver, 13 - reactor, 14 - measuring tank for aluminium sulphate, 15 - measuring tank for liquid glass, 16 - measuring tank for alkali or soda, 17 combined drier, 18 - filtrate receiver, 19 - ground pigment receiver, 20 - vapour condenser, 21 finished product hopper.

In accordance with the above-given diagram, titania ore is fed from hopper 1 into bead mill 4 for future dechlorination. Besides, the specified amount of chemically purified water and caustic magnesite is also fed from tank 3 and hopper 2 to bead mill 4 . In bead mill 4, while heating, the titania ore is ground to the specified size, and the chlorine bound by caustic magnesite passes into the solution according to the reaction (1):

$$
\mathrm{MgO}+2 \mathrm{HCl}=\mathrm{MgCl}_{2}+\mathrm{H}_{2} \mathrm{O}
$$

The obtained pigment slurry is subsequently fed from bead mill 2 to filter press 6 by pump 5, whereas the filtrate from filter press 6 is fed to collector 7, with the obtained paste fed primarily to centrifuge 8 and finally to hydroseparator 9 where the paste is separated into coarse and fine fractions. The coarse paste fraction is subject to additional microniziation in steam-jet mill 11 , then refed to the centrifuge 8 , whereas the fine paste fraction is fed from collector 12 to reactor 13 for the final surface treatment. Reagents in specified amounts are fed into reactor 13 in the following sequence: firstly, aluminium sulphate and sodium carbonate, and secondly, liquid glass and alkali. The obtained stabilized slurry is next fed to filter press 6 , and then flushed from the filter press surface with condensate supplied from vapour condenser 20 as well as chemically purified water, to the condition with complete absence of water-soluble salts in the obtained paste.

The flushed paste is fed to combined dryer 17, then dried and ground to the specified size. The ground pigment, during the accumulation process, is transferred by the auger to hopper 19, from where, when needed, is either packed into containers or additionally micronized in steam jet mill 11, and finally sent to finished product hopper 21. Titania modified by the described technology fully complies with its technical requirements. The combined feed of aluminium-, silicon-, and zinc-containing additives at the stage of titanium tetrachloride oxidation provides good physical and technical properties and weather resistance of the yielded titania [26]. 


\section{Conclusions}

The study have stated that

1. The most promising raw material for the yield of titania by the chlorination method is a titanium-quartz ore deposit.

2. The most economically reasonable method is to supply rutile concentrate from ore processing factories with a content of titania equal to $94 \ldots 95 \%$.

3 . The quality of titania produced with titanium concentrate chlorination, and titanium tetrachloride oxidation with oxygen using arc plasmatron heating in this unit is on a level with the best foreign samples.

4. The combined feed of aluminium-, silicon-, and zinc-containing additives at the stage of titanium tetrachloride oxidation provides high properties of the yielded titania.

\section{References}

1. Harry G. Brittain, Gary Barbera, Joseph DeVincentis, Ann Newman, Titanium Dioxide, Analytical Profiles of Drug Substances and Excipients 21 (1992)

2. J.H. Braun, Titanium dioxide - A review, Journal of Coatings Technology 69, 868 (1997)

3. Ann M. Thayer, Titanium Dioxide, Chemical \& Engineering News 76, 10 (1998)

4. Robert A. Erb, Properties Of Titanium Dioxide, Chemical \& Engineering News 93, 30 (2015)

5. Xiaolan Kang, Sihang Liu, Zideng Dai, Yunping He, Xuezhi Song, Zhenquan Tan, Titanium Dioxide: From Engineering to Applications, Catalysts 9, 2 (2019)

6. Xianfeng Luo, Zhongpeng Zhu, Ye Tian, Jun You, Lei Jiang, Titanium Dioxide Derived Materials with Superwettability, Catalysts 11, 4 (2021)

7. Adawiya Haider, Zainab N. Jameel, Imad H.M. Al-Hussaini, Review on: Titanium Dioxide Applications, Energy Procedia 157 (2019)

8. Jijian Xu, Zhangliu Tian, Guoheng Yin, Tianquan Lin, Fuqiang Huang, Controllable reduced black titania with enhanced photoelectrochemical water splitting performance, Dalton Transactions 46, 4 (2016)

9. Shaohua Liu, Zhihuan Zhao, Zhizhong Wang, Photocatalytic reduction of carbon dioxide using sol?gel derived titania-supported CoPc catalysts, Photochemical and Photobiological Sciences 6, 6 (2007)

10. Fan Yang, Ruizhuang Yang, Lin Yan, Jiankun Wu, Xiaolin Liu, Lirong Yang, Minglong Zhong, Xuan Luo, Lin Zhang, Enhancement of Titania Photoanode Performance by Sandwiching Copper between Two Titania Layers, Materials 13, 19 (2020)

11. Jinghang Li, Huimin Zang, Shun Yao, Zicheng Li, Hang Song, Photodegradation of Benzothiazole ionic liquids catalyzed by titanium dioxide and silver-loaded titanium dioxide, Chinese Journal of Chemical Engineering 28, 5 (2020)

12. Navpreet Kaur, Mandeep Singh, Abderrahim Moumen, Giorgio Duina, Elisabetta Comini, 1D Titanium Dioxide: Achievements in Chemical Sensing, Materials 13, 13 (2020)

13. S. N. Gladkikh, S. E. Loginova, L. G. Gerasimova, Ekaterina Shchukina, The Effect of Titanium Dioxide on Heat Stability of Sealants, Polymer Science Series D 13, 2 (2020) 
14. Rahul Mane, Ramkrishna Sahoo, Kumaar Swamy Reddy B, R. Vijay, Bharat Panigrahi, Pramod Borse, Dibyendu Chakravarty, Doping-induced coloration in titania, Journal of the American Ceramic Society 104, 4 (2021)

15. Kai Hu, Kai Tang, Xuewei Lv, Jafar Safarian, Zhiming Yan, Bing Song, Modeling Viscosity of High Titania Slag, Metallurgical and Materials Transactions B 51, 5 (2020)

16. Karima Boutarfa, Amel Saoudi, Khedidja Boufligha, Houneida Benbouzid, Racha Mihoub, Mourad Bensouilah, The Effect of Titanium Dioxide Nanoparticles Against Cyanobacterial Microorganisms, Egyptian Journal of Aquatic Biology and Fisheries 25, 3 (2021)

17. Himanshu Kachroo, Anjana Pandey, Saumya Srivastava, Thomas Yeager, Cytotoxicity Evaluation of Titania and Silver Doped Titania on Human Colorectal Cells, Sensor Letters 18 (2021)

18. Brigitte Dreno, A. Alexis, B. Chuberre, M. Marinovich, Safety of titanium dioxide nanoparticles in cosmetics, Journal of the European Academy of Dermatology and Venereology 33, S7 (2019)

19. Daniel Ziental, Beata Czarczynska-Goslinska, Dariusz T. Mlynarczyk, Arleta Glowacka-Sobotta, Beata Stanisz , Tomasz Goslinski, Lukasz Sobotta, Titanium Dioxide Nanoparticles: Prospects and Applications in Medicine, Nanomaterials 10, 2 (2020)

20. Masato Ueda, Chihiro Sawatari, Tomoyuki Takahashi, Hiroaki Tsuruta, Hidenobu Tokushige, Hirohisa Hikosaka, Daigo Yonetsu, Masahiko Ikeda, Utilisation of Titanium and Titanium Dioxide as Scaffolds for Proliferating Coral Reef, Materials Science Forum 1016 (2021)

21. Lili Zhang, Ting-An Zhang, Guozhi Lv, Weiguang Zhang, Tingting Li, Xuejiao Cao, Separation and Extraction of Scandium from Titanium Dioxide Waste Acid, JOM: the journal of the Minerals, Metals \& Materials Society 73, 5 (2021)

22. Galina Vitkina, A. N. Dmitriev, Roman V. Alektorov, Elena A. Vyaznikova, Processing of Agglomerates and Pellets Containing Various Amounts of Titanium Dioxide, Materials Science Forum 1026 (2021)

23. Ksü Mühendislik Bilimleri Dergisi, Serdar Göçer, Zeynep Zaimoglu, Kevser Cirik, Synthesis Of Titanium Dioxide (TiO2), Kahramanmaraş Sütçü İmam Üniversitesi Mühendislik Bilimleri Dergisi 23, 4 (2020)

24. V. F. CHuprik, V. N. Kuz'min, I. V. Barsukova, N.YA. Dubrovskaya, Razlozhenie sil'noizmenenny titansoderzhashchih koncentratov sernoj kislotoj (Decomposition of highly modified titanium-containing concentrates with sulfuric acid), Lakokrasochnye materialy $\mathrm{i}$ ih primenenie 4, pp. 15-16 (1976)

25. A. A. Guzairova, Issledovaniya stroenie dvojnogo elektricheskogo sloya agregativnoj ustojchivosti gidrodispersij rutila (Investigation of the structure of the electric double layer of aggregate stability of rutile hydrodispersions) (Avtoref. dis.... kand. him. nauk, 1975)

26. Novoe v tekhnologii polucheniya dvuokisi titana, Sbornik statej, Chelyab. filial Nauch.-issled. i proektnogo in-ta neorgan. pigmentov $i$ sudovyh pokrytij (Pod red. kand. tekhn. nauk I. P. Dobrovol'skogo i dr.) (Chelyabinsk, Yuzh.-Ural. kn. izd-vo, 1976) 